\title{
Design Of Speed Controller For Three Phase Induction Motor Using Fuzzy Logic Approach
}

\author{
Farazdaq R.Yaseen ${ }^{1}$,Walaa H. Nasser ${ }^{2}$ \\ ${ }^{1,2}$ Control and System Engineering Department, Unversity of Technology, Baghdad, Iraq \\ drfarazdq@gmail.com,walaahussain321@gmail.com
}

\begin{abstract}
The use of Induction Motor (IM) has been increased becuase of it's robust construction, simple design, and low cost. This paper presents a methodology for the application and performance of Fuzzy like PI Controller to set the frequency of Space Vector Pulse-Width modualtion (SVPWM) Inverter applied to closed loop speed control of IM. When the controller is used with current controller, the quadratic component of stator current is estimated by the controller. Instead of using current controller, this paper proposes estimating the frequency of stator voltage. The dyanamic modelling of the IM is presented by dq axis theory. From the simulation results, the superiority of the suggested controller can be observed in controlling the speed of the three-phase IM.
\end{abstract}

Index Terms - Induction Motor , Fuzzy PI control , and SVPWM.

\section{INTRODUCTION}

Three phase induction motors can be considered as one of the most widely used motors in industrial control and automations, due to their robustness, reliability, less maintenance and high durability. Control techniques of IM can be classifed into two main types: scalar control and vector control methods. Scalar control is also known as Voltage to frequency ratio (V/f) control, in which the construction of (V/f) controller is very simple and usually used without speed feedback. But, the performance of this controller doesn't obtain the required accuracy in both the torque and speed responses and this is a consequence to the fact that the flux and the torque of the stator are not controlled directly [1].

On the other hand, vector control method which is used in this paper presents better performance compared with (V/f) controller. It can be classified into: Field Oriented Control (FOC) and Direct Torque Control (DTC)[1,2].

The conventional vector control system uses the classical PI controller in the closed loop speed controller due to it's simple and stable design. Nevertheless, unpredicted variation in the conditions of the load or environmental factors would generate high overshoot, oscillation of motor speed- torque charcteristic long settling time and thus lead to retrogradation in the performance of the drive.

To overcome the convientioal controller draw back, a developed controller based on the principle of the Fuzzy Logic Controller (FLC) could be utilized instead of the classical PI controller. The main advantages of such controller are simple constuction as well as the possibility to design without knowing the exact mathematical model of drive plant [3].

A review of many previous researches for controlling the IM is presented as follows:

Mannan, M. A., et al., 2004 [4] proposed that the Field-Oriented Control (FOC) method of IM drive is applied using the fixed gain PI controller. For more improvement in the performance of PI controller, a new FLC based self-tuning PI control system for controlling the speed of IM drives with FOC method was used. The simulation results showed that the proposed speed controller gives a better performance than that of the conventional PI speed controller when compared to the PI speed controller in attaining the desired output speed. 
Satean T., et al., 2007 [5] presented the design and the implementation of a voltage source inverter type SVPWM for controlling the speed of the IM. Beside that, a FLC was inserted into the system in order to keep the motor speed to be constant once the load is changed. The speed of the IM is tested under load condition and the obtained results confirm the ability of the suggested controller.

Salima .M., et al., 2008 [6], with an aim to improve the FOC, used the Input-Output linearization technique as a control method of the IM to track the torque and the rotor flux. A comparative study was done between the performances of the proposed controller and FOC method.

The Simulation results prove the effectiveness of the proposed method.

Tripura P., et.al. , 2011 [3] proposed a FLC based speed control system for three phase IM, where an advanced speed control system based on the fuzzy set theory for a VSI type PWM fed indirect field oriented controlled IM drive system has been investigated. The performances of the intelligent controller and the classical PI controller were compared; the result showed that the FLC has faster response and better performance as compared with PI controller.

Nageswara Rao.M. and Rajani. A. (2013) [7] presented a methodology for the implementation of a rule-based FLC applied to a closed loop V/f speed control. The designed FLC performance was weighed against that of a classical PI controller. The simulation results confirm that the control of the IM by using the Fuzzy implementation has more advantages than the basic PI controller.

Menghal, P.M., et al., 2014 [8] presented a methodology for implementation of a rule-based FLC applied to a closed loop V/f speed control of IM. The conventional PI controller and the designed FLC have been compared, and the obtained simulation results prove that the FLC can achieve better system performance than that of the conventional PI controller.

Kamini Devi, et al., (2015) [9] presented a rule-based FLC utilized for a closed loop scalar V/f speed control of IM. The aim of using the FLC in this system is to maintain the speed of the motor when the load is changed. The implemented FLC presented a slightly superior dynamic performance.

TEENA PATIL, P. P. MAHAJAN, 2016 [10] presented the simulation of closed loop V/f speed control of three-phase IM. The motor speed can be regulated by FLC. In the vector control system, the actual speed of the motor is compared with the reference speed, and the resulting speed error (e) and its rate of change represent the inputs variables to the FLC, on the other hand, the output of this controller is the frequency. The control strategy tries to keep the ratio of the voltage-frequency of IM to be constant. The performance of this controller is compared with those of PI and PID controllers and it was found that the proposed controller can achieve superior performance over the PI and the PID controllers.

In this paper, the speed controller for a squirrel-cage IM with FOC method is modeled based on FLC technique in Simulink environment, we proposed estimating the frequency fed a voltage source invertor (SVPWM) which converts frequency into three phase voltage signal and these signals are given to the IM, which controls the speed of this motor.

\section{MATHEMATICAL MODELLING OF IM}

The dynamic model of 3 Phase IM in the stationary refrence frame can be drived by the voltage and torque differential equations. The d-q equivalent circuit of IM is obvious in Fig.1 [1,11].

Stator flux rate of change in dq frame can be described by $[1,12]$ :

$$
\begin{aligned}
& v_{d s}=R_{S} i_{d s}+\frac{d}{d t} \lambda d_{s} \\
& v_{q s}=R_{S} i_{q s}+\frac{d}{d t} \lambda q_{s} \\
& 0=R_{r} i_{q r}+\frac{d}{d t} \lambda q_{r}-\omega_{r} \lambda_{d r}
\end{aligned}
$$




$$
0=R_{r} i_{d r}+\frac{d}{d t} \lambda d_{r}-\omega_{r} \lambda_{q r}
$$

It is clear that $v_{d r}=v_{q r}=0$.

$v_{d s}$ and $v_{q s}$ are the dq voltages of the stator, $i_{q s}$ and $i_{d s}$ are the dq currents of the stator $\lambda d_{s}$ and $\lambda q_{s}$ are the dq stator flux $\lambda d_{r}$ and $\lambda q_{r}$ are the dq rotor flux , $R_{S}$ and $R_{r}$ are the resistance of the stator and the rotor, respectively, while $\omega_{r}$ represents the motor angular speed. The developed torque $T_{e}$ can be described in the vector form as:

$$
T_{e}=\frac{3}{2}\left(\frac{P}{2}\right)\left(\lambda_{d m} i_{q s}-\lambda_{q m} i_{d s}\right)
$$

Where $\lambda_{d m}$ and $\lambda_{q m}$ are the direct and quadratic mutual flux, respectivly, and $\mathrm{P}$ is the number of motor poles.

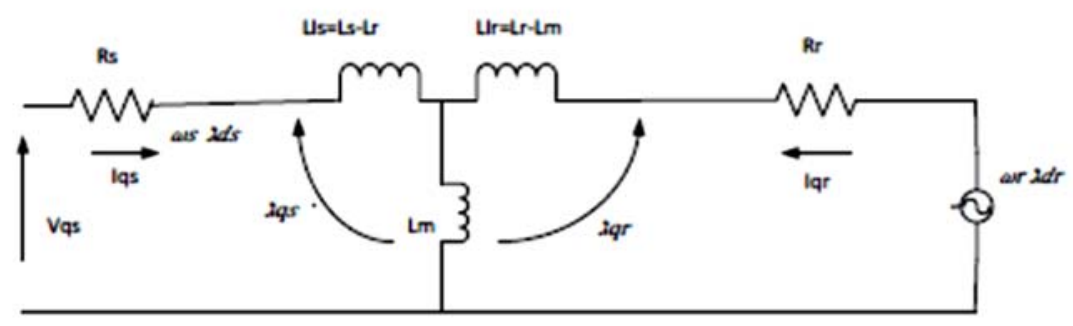

(a) q-circuit

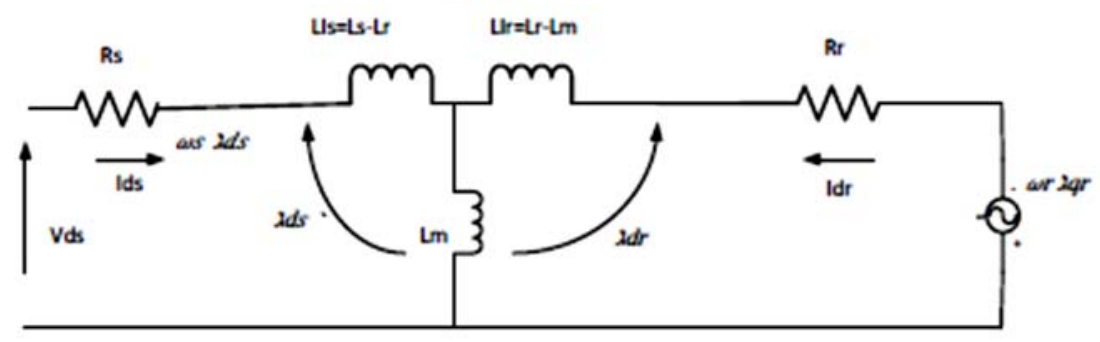

(b) d-circuit

Fig.1. The EQUivalent CirCuIT OF IM.

The mechanical dynamic equation which relates the motor characteristic speed $\omega_{\mathrm{r}}$ to the torque is:

$$
\begin{aligned}
& T_{e}-T_{L}=\left(\frac{2}{p}\right) J \frac{d \omega_{r}}{d t} \\
& \dot{\omega}_{r}=\left(\frac{1}{J}\right)\left(\frac{p}{2}\right)\left(T_{e}-T_{L}\right)
\end{aligned}
$$

Where $T_{L}$ represents the external load torque and $\mathrm{J}$ represents the motor moment of inertia.

The dynamic model of the IM can be expressed in Fig. 2. In order to obtain the 2 phase current of stator and rotor of the IM, the voltages will be converted into 2-phase in the dq-axes using Parks transformation, in the last stage, inverse park transformation is applied to get 3-phase current using the following conversion equation:

$$
\left[\begin{array}{l}
i_{a} \\
i_{b} \\
i_{c}
\end{array}\right]=\left[\begin{array}{cc}
1 & 0 \\
\frac{-1}{2} & \frac{-\sqrt{3}}{2} \\
\frac{-1}{2} & \frac{\sqrt{3}}{2}
\end{array}\right]\left[\begin{array}{l}
i_{q}^{s} \\
i_{d}^{s}
\end{array}\right]
$$




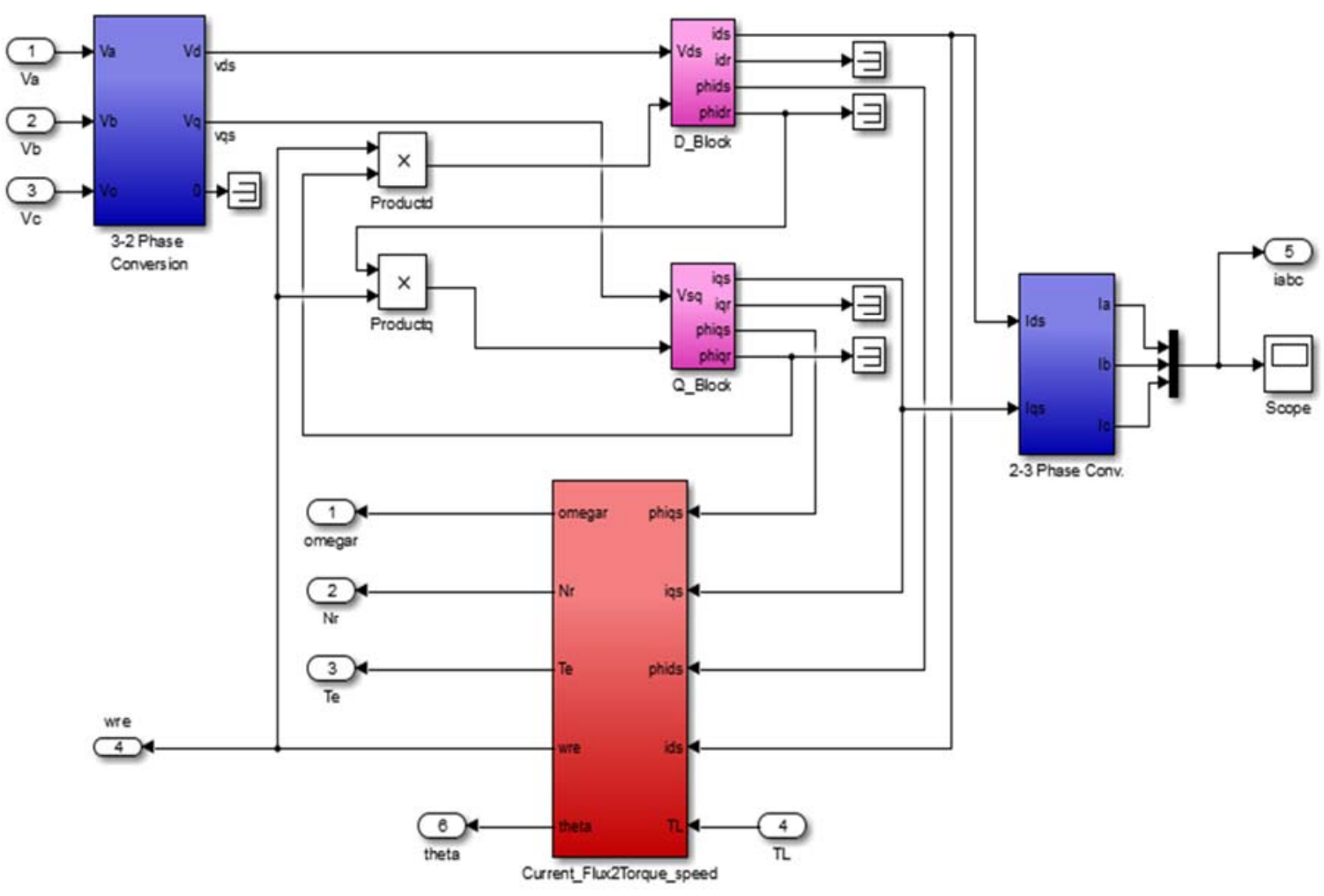

Fig 2. A: DyNAMiC Model of IM .

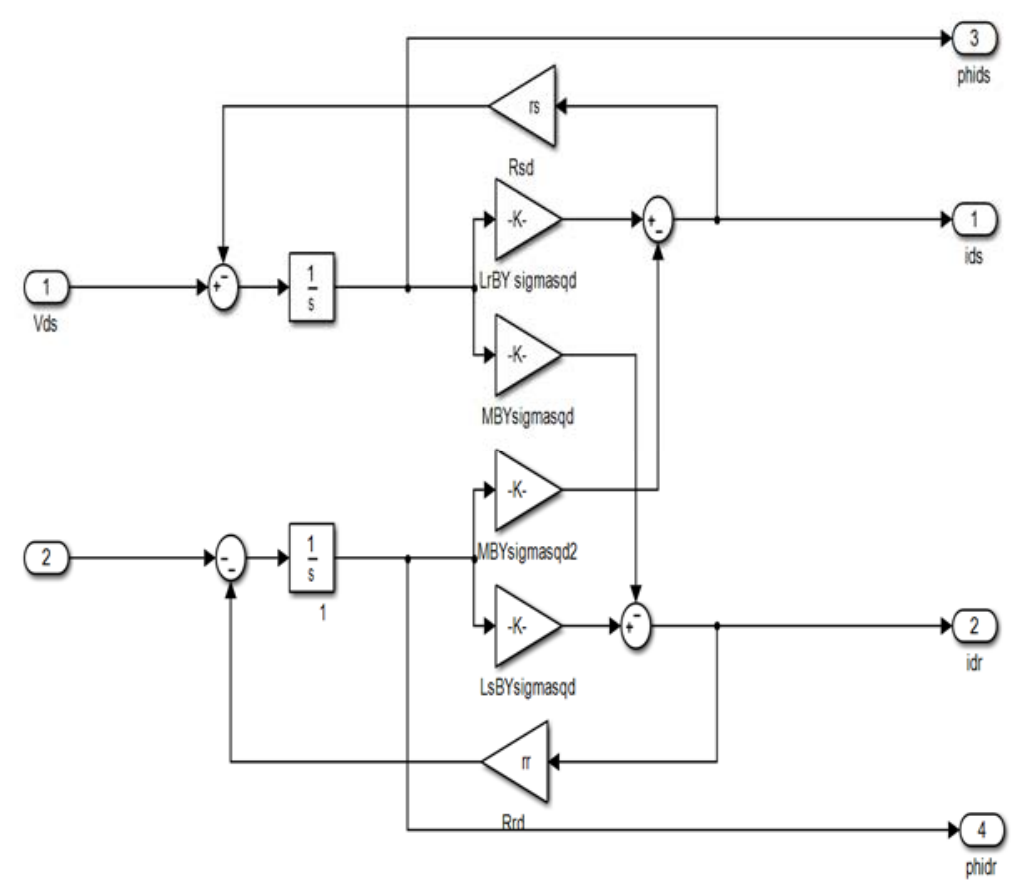

Fig 2 . B : DYNAMic Model of IM, D_BLOCK. 


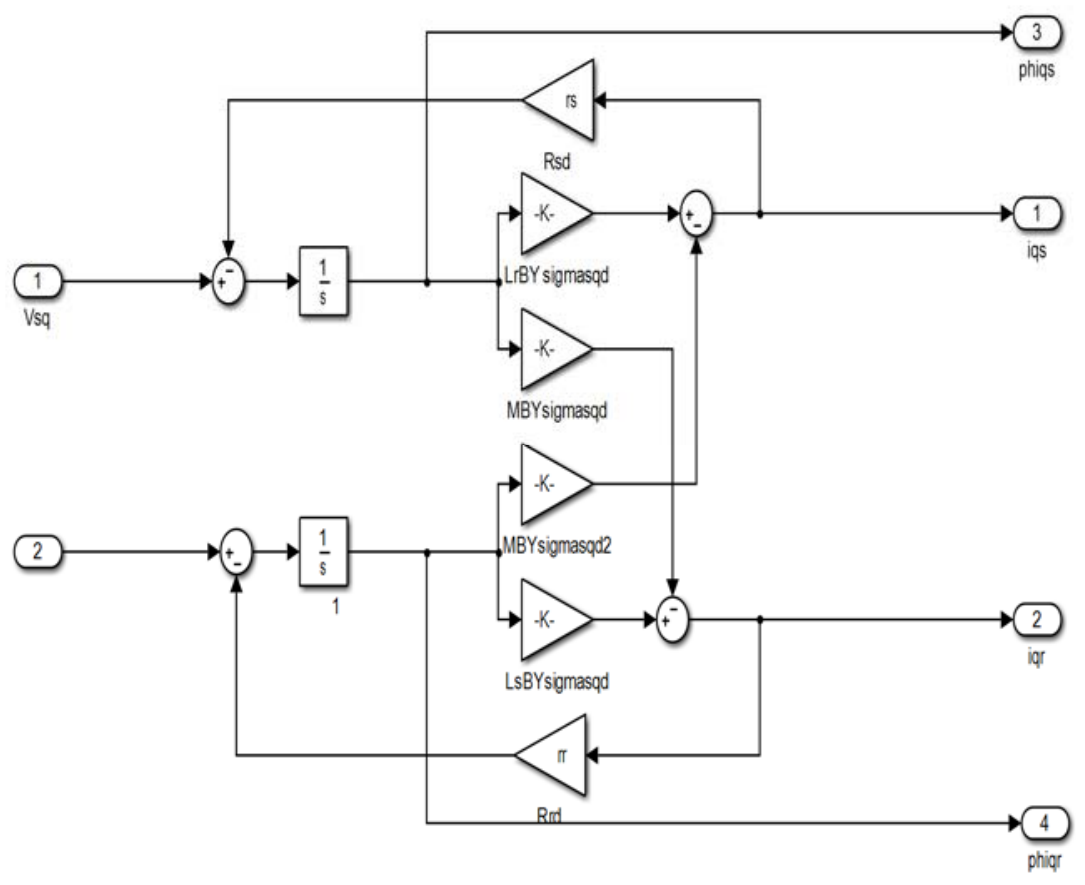

FIG 2 . C : DYNAMIC MODEL OF IM, Q_BLOCK.

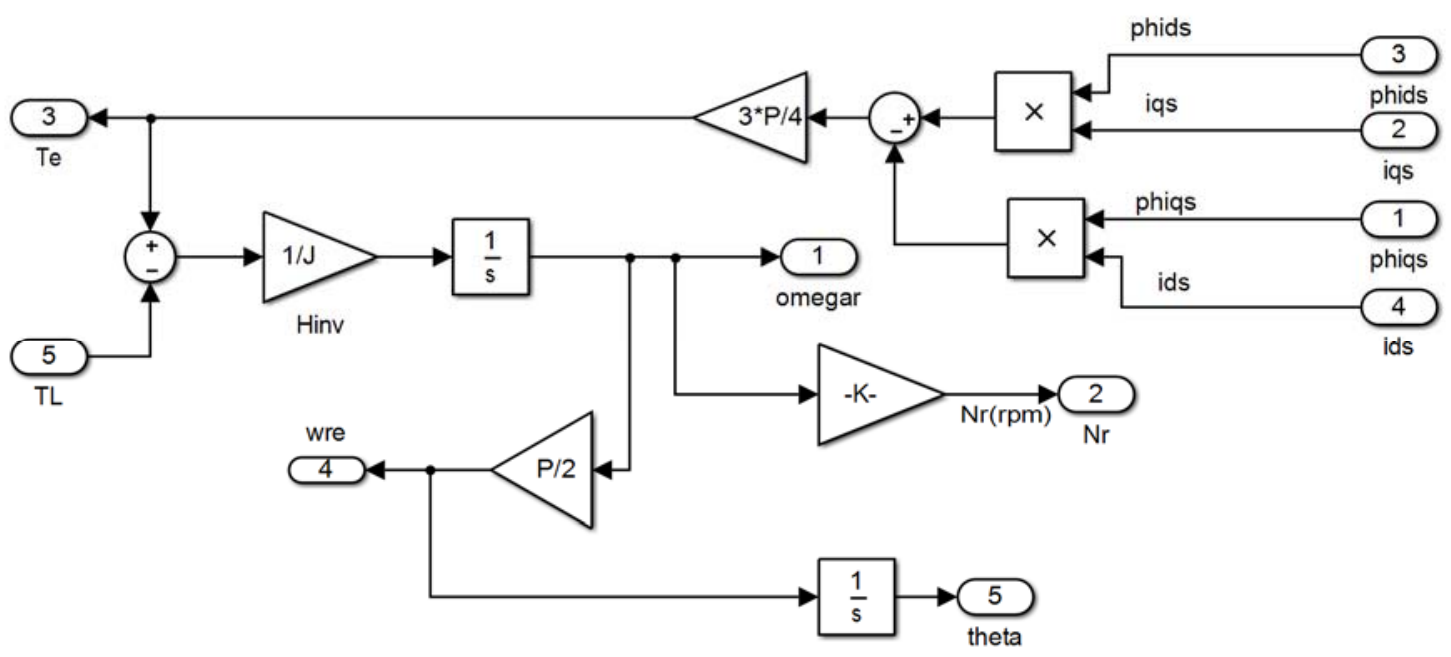

FIG2. D: DYNAMIC MODEL OF IM, THE MECHANICAL DYNAMIC EQUATION .

\section{SPACE VECTOR PULSE-WIDTH MODUALTION (SVPWM)}

This inverter consists of three legs with six controlled swithches $\left(S_{1}\right.$ to $\left.S_{6}\right)$. The idea is to generate a vector with an amplitude $\mathrm{V}_{\text {ref }}$ which moves with an angle $(\alpha)$ across six sectors, as shown in Fig.3. The SVPWM can be performed in three steps $[13,14]$ :

- Step 1. Calculation of Vref, and angle $(\alpha)$ from $V_{d}$ and $V_{q}$

- Step 2. Calculation of the time duration $\mathrm{T}_{1}, \mathrm{~T}_{2}$, and $\mathrm{T}_{0}$

- Step 3. Calculation of the switching time of each switching device $\left(\mathrm{S}_{1}\right.$ to $\left.\mathrm{S}_{6}\right)$ 


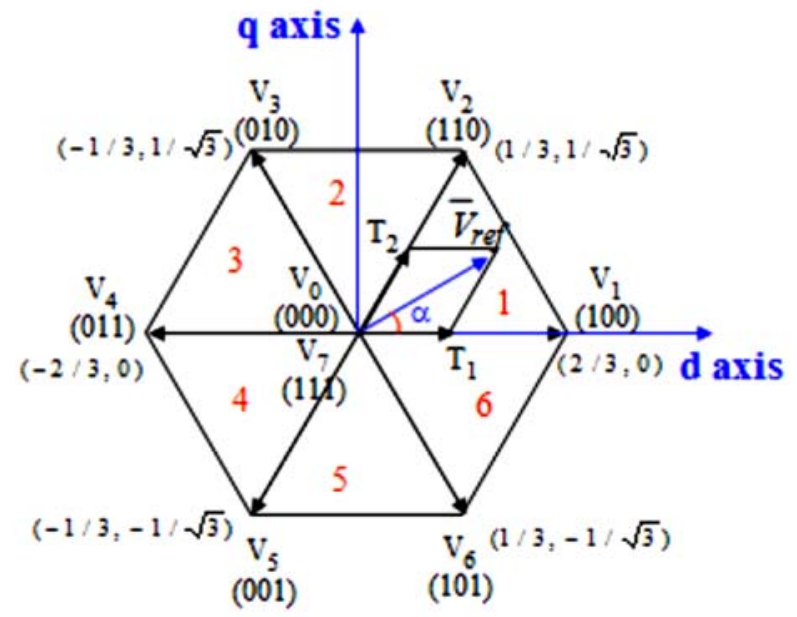

Fig.3. THE BASIC SWITCHING VECTORS AND SECTORS.

The Implementation of SVPWM is presented in Fig.4.
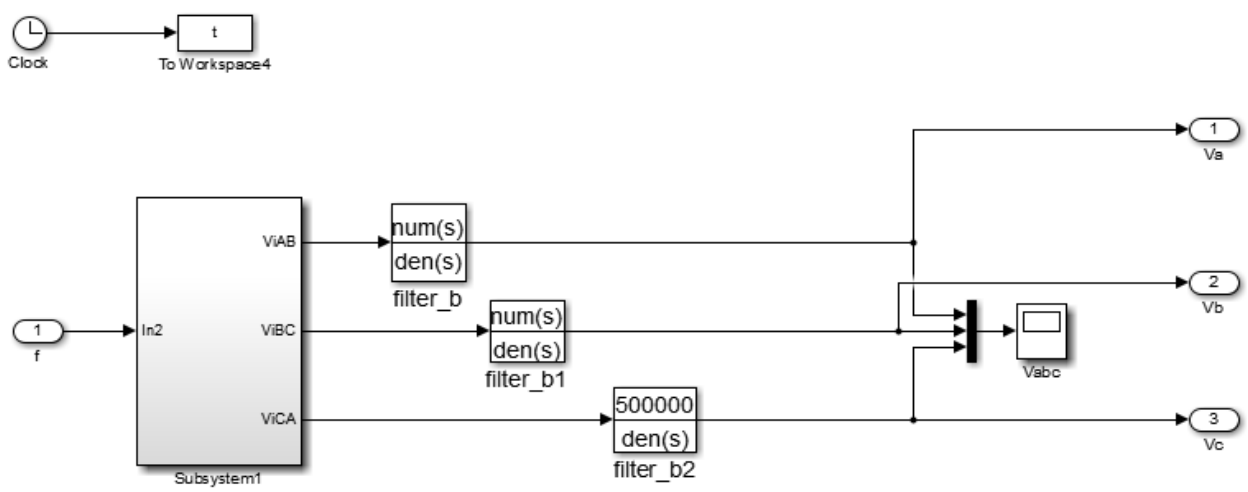

FIg. 4 A: Model of SVPWM [13].

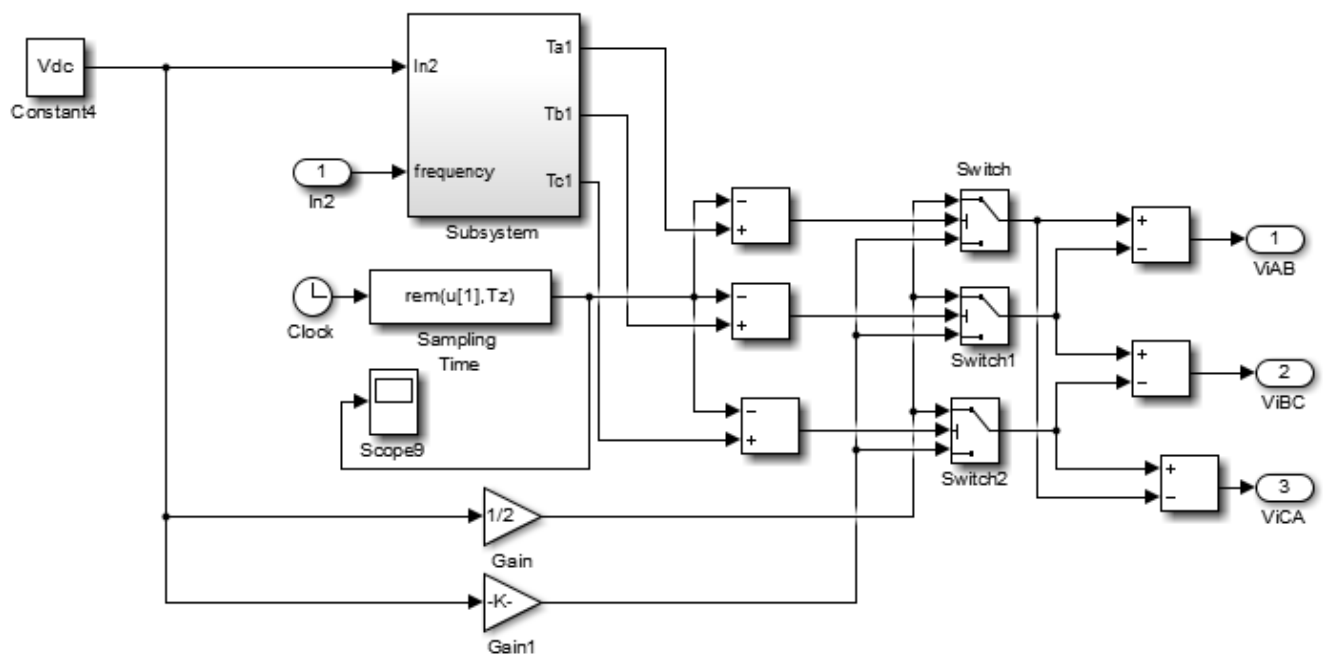

FIG. 4 B: Model OF SVPWM. 


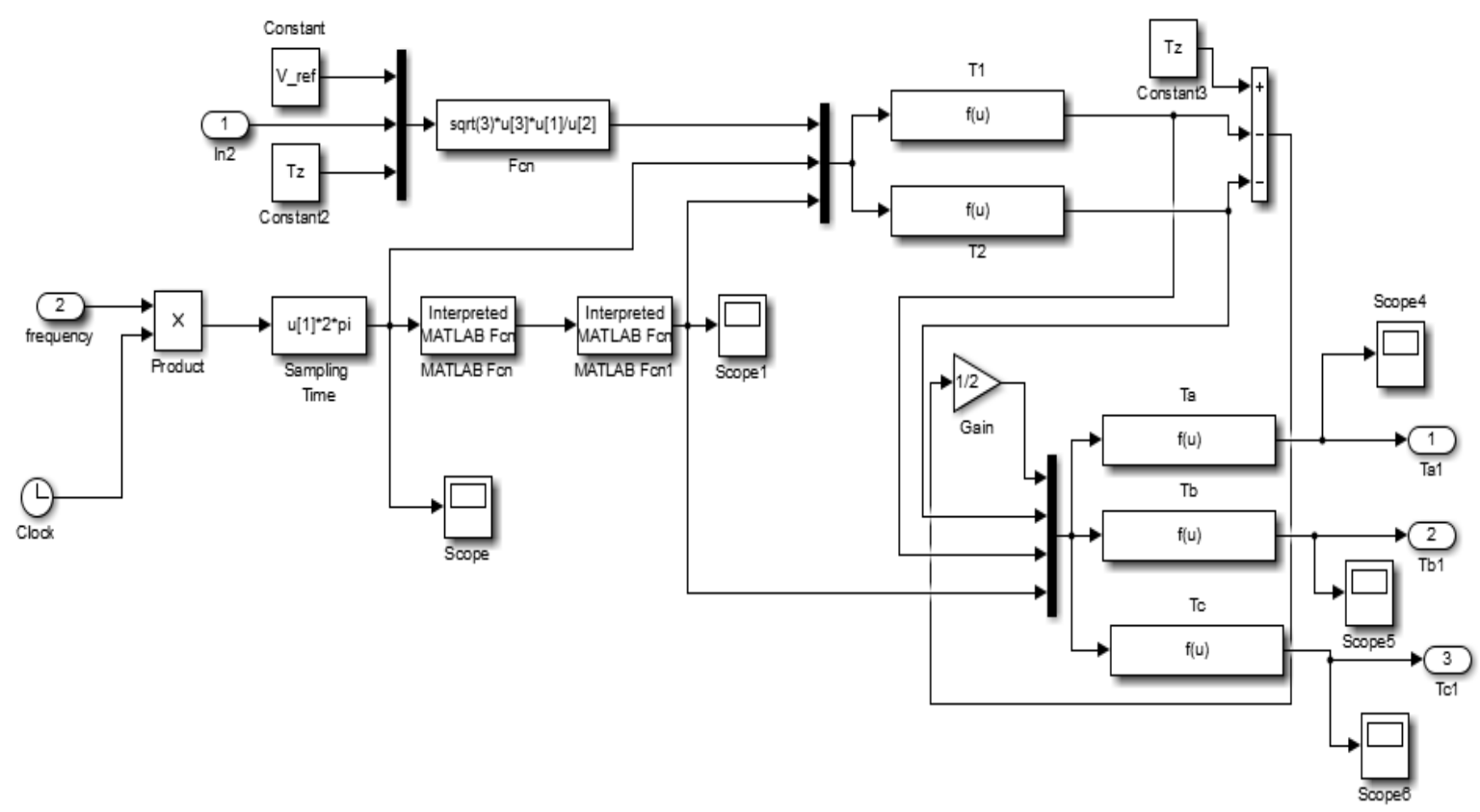

FIG. 4 C: MODEL OF SVPWM.

\section{PI CONTROLLER}

A PI controller responds to an error signal which represents the difference between the desired and the actual signals in the closed loop control, and tries to modify the controlled value until the required system response can be obtained. The main feature of using the classical PI controller is that it can be adjusted empirically by adjusting the value of one or more gain and observing the system response change. In the PI controller model shown in Fig.5, speed error is minimized between reference speed and measured speed and the output of the controller is the frequency, which is fed to the voltage source inverter that converts frequency into three phase voltage signal and these signals are fed to the IM, which controls the speed of the motor $[7,8,11]$.

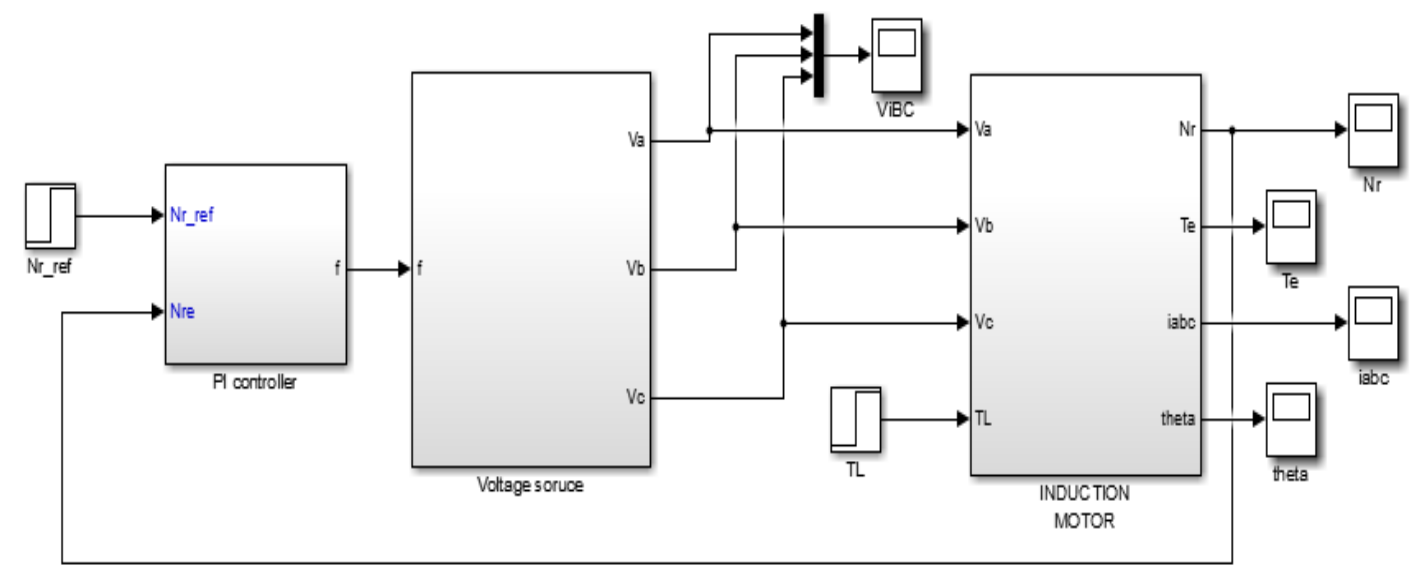

FIG. 5: PI CONTROLLER MODEL

\section{FUZZY LIKE PI CONTROLLER DESIGN}

Fuzzy logic controller (FLC) is based on the concept of the knowledge base which in turn depends upon the numerous if-then rules, which are similar to the way of thinking of the human being operator. As opposed to the other control approaches, FLC is more common because no complex mathematical knowledge is required [8]. The performance of the FLC is dependent on the membership functions, the 
distribution of these membership and the fuzzy rules which are used in the description of the control algorithm. No systematical method is used to set the parameters of the controller accurately. Tuning the FLC can be considered as an iterative process because that demands modifications in both the membership functions and the control rules. The reconstruction of the system can be achieved by taking into account the response of the system regulator and modification of the fuzzy sets of both the input variables (e and de/dt) and output variable (du/dt) until the proper response can be attained $[15,16,17]$. The Fuzzy like PI is proposed to estimate the required frequency to drive the motor at a constant speed. When the motor is loaded, the motor speed will be reduced and the Fuzzy like PI Controller will increase the frequency by a suitable amount. The details of the Fuzzy like PI Controller are displayed in Fig.6.

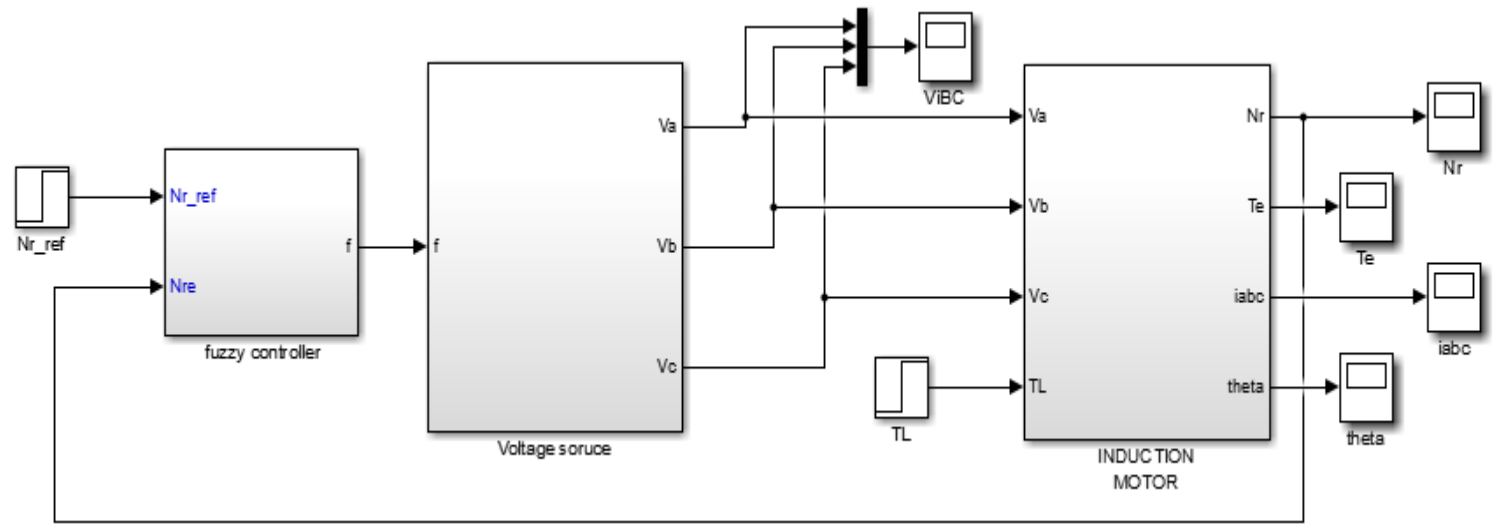

FIG. 6 A: FUZZY LIKE PI CONTROLLER MODEL

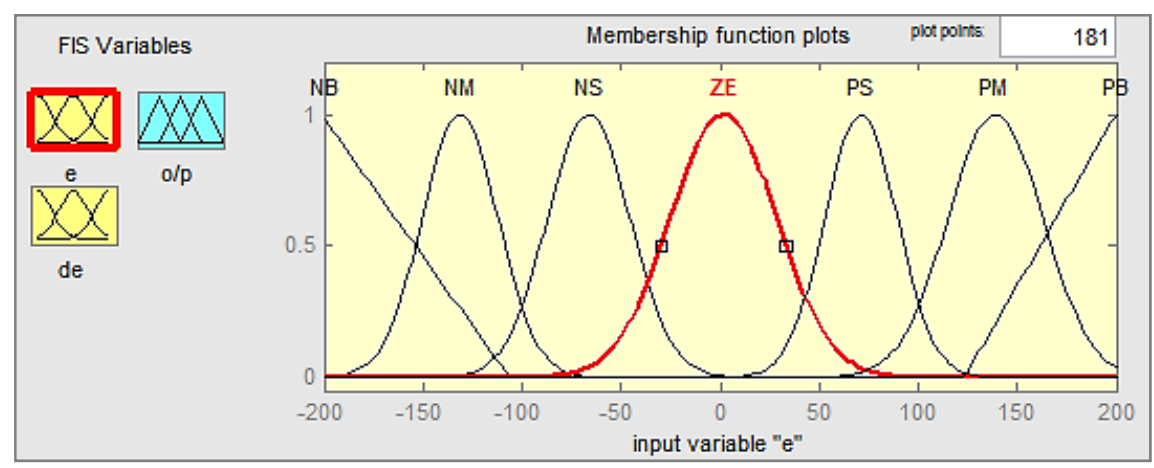

FIG. 6 B : MEMBERSHIP FUN. SPEED ERROR AND CHANGE OF SPEED ERROR.

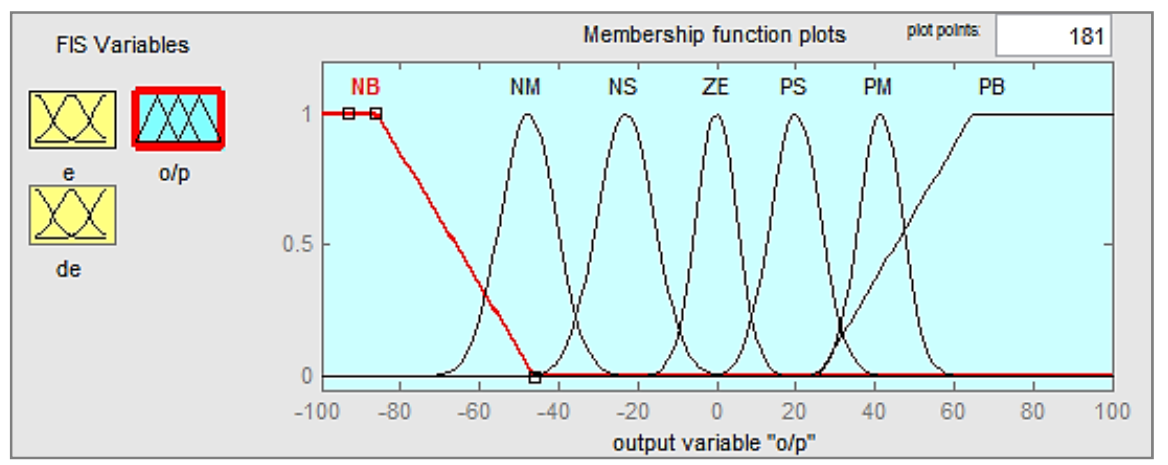

FIG. 6 B : MEMBERSHIP FUN. OF CONTROLLER OUTPUT 


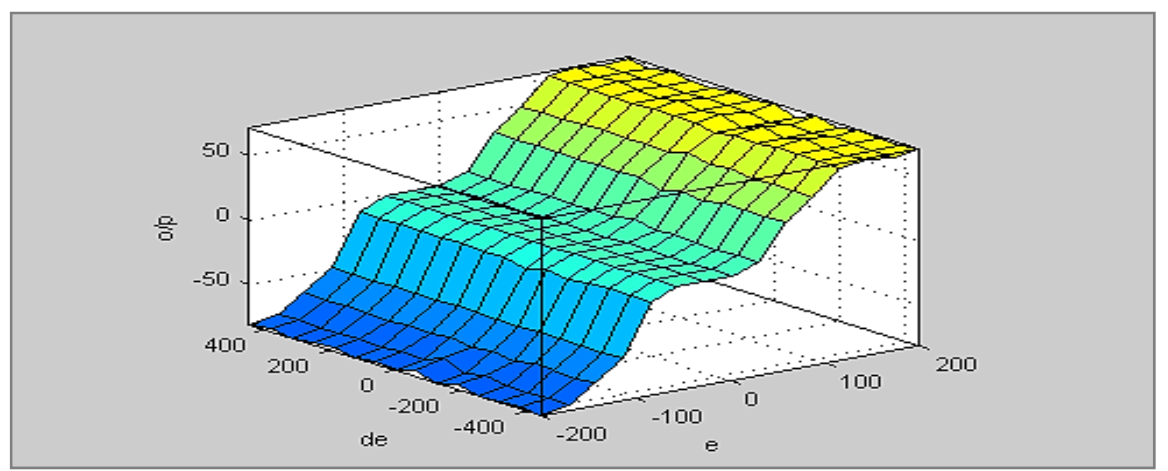

FIG. 6 C : SURFACE VIEW OF THE INPUT AGAINST THE OUT PUT

TABLE 1: FuZZY Like PI RULE

\begin{tabular}{|c|c|c|c|c|c|c|c|}
\hline $\mathbf{e} / \mathbf{A} \mathbf{e}$ & $\mathbf{N B}$ & $\mathbf{N M}$ & $\mathbf{N S}$ & $\mathbf{Z}$ & $\mathbf{P S}$ & $\mathbf{P M}$ & $\mathbf{P B}$ \\
\hline $\mathbf{N B}$ & NB & NB & NM & NM & NS & NS & $Z$ \\
\hline NM & NB & NM & NM & NS & NS & $Z$ & PS \\
\hline NS & NM & NM & NS & NS & Z & PS & PS \\
\hline $\mathbf{Z}$ & NM & NS & NS & Z & PS & PS & PM \\
\hline PS & NS & NS & Z & PS & PS & PM & PM \\
\hline PM & NS & Z & PS & PS & PM & PM & PB \\
\hline PB & Z & PS & PS & PM & PM & PB & PB \\
\hline
\end{tabular}

\section{SIMULATION RESULT}

The IM Modeling and Simulation design of the classical PI and Fuzzy like PI controllers are done by using MATLAB/SIMULINK. The parameters of the IM model are shown in Table 2, while Fig .7 shows the simulation model of both the Fuzzy like PI and the classical PI controllers, Fig .8, Fig 9 and Fig 10 show speed, current and torque response of the Fuzzy like PI controller, respectively.

TABLE 2: The PARAMETERS OF IM

\begin{tabular}{ccc}
\hline Parameters & Values & Units \\
\hline Voltage & 200 & $\mathrm{~V}$ \\
Stator resistance & 6.03 & $\Omega$ \\
Rotor resistance & 6.085 & $\Omega$ \\
Stator inductance & $489.3 \mathrm{e}-3$ & $\mathrm{H}$ \\
Rotor inductance & $489.3 \mathrm{e}-3$ & $\mathrm{H}$ \\
Mutual inductance & $450.3 \mathrm{e}-3$ & $\mathrm{H}$ \\
Poles & 4 & --- \\
Moment of Inertia & 0.00488 & Kg.m ${ }^{2}$ \\
\hline
\end{tabular}




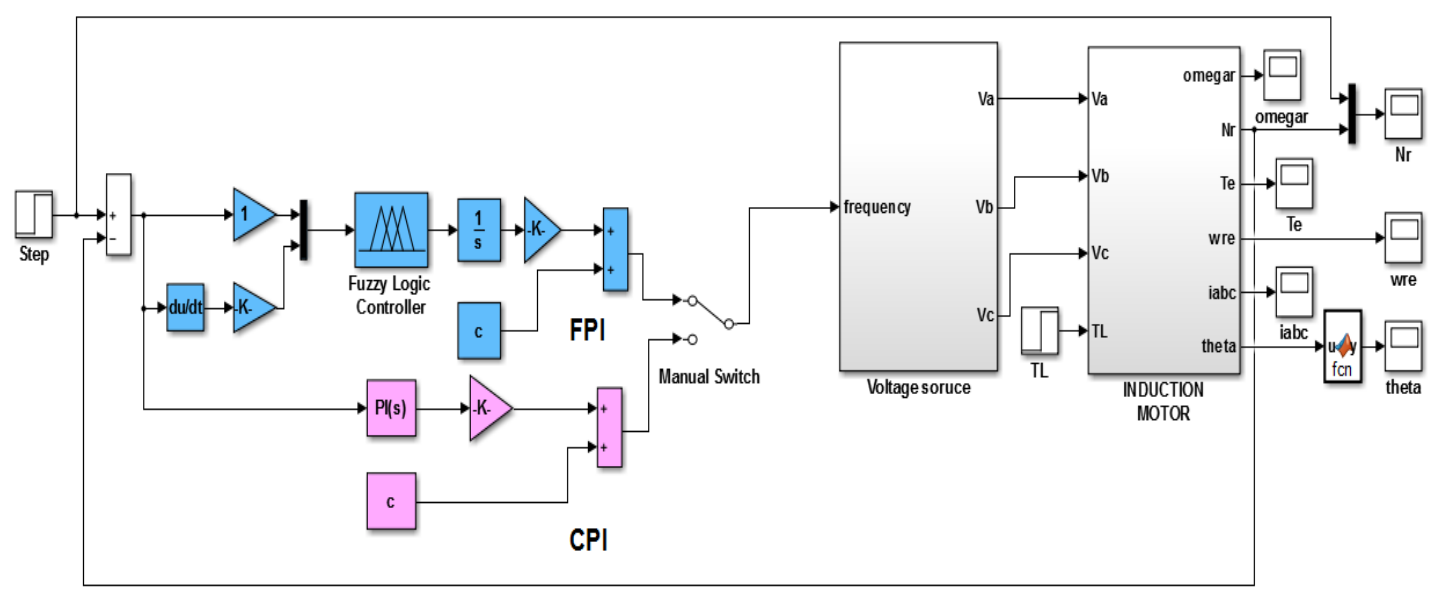

Fig. 7. SimUlation MODEL OF BOTH FuZZY LIKE PI AND PI CCONTROLLER

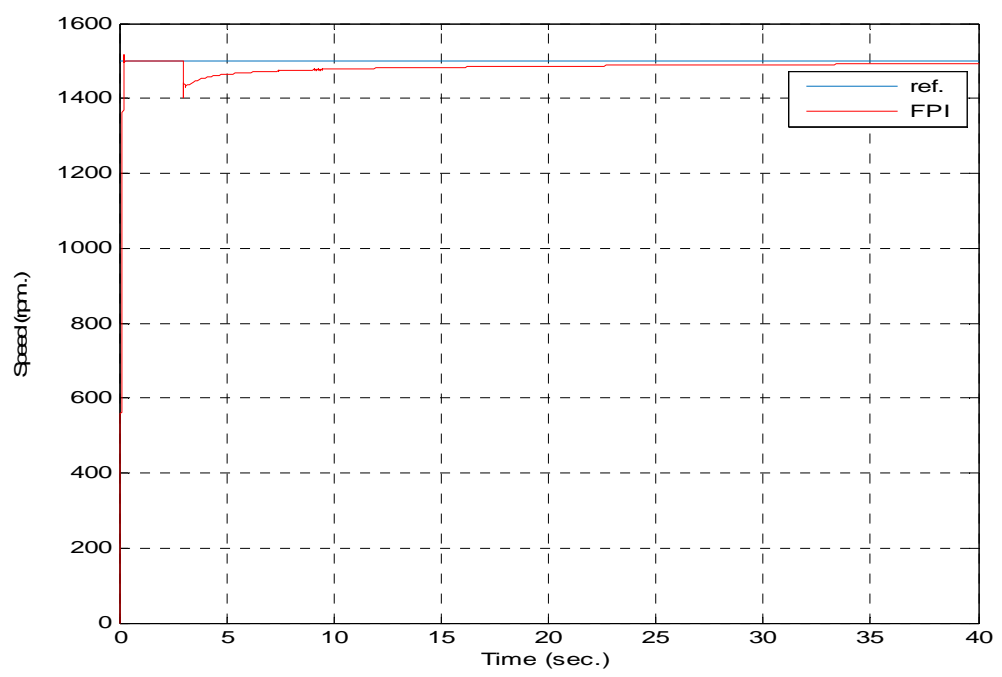

Fig. 8. SPEED RESPONSE OF FUZZY LIKE PI CONTROLLER

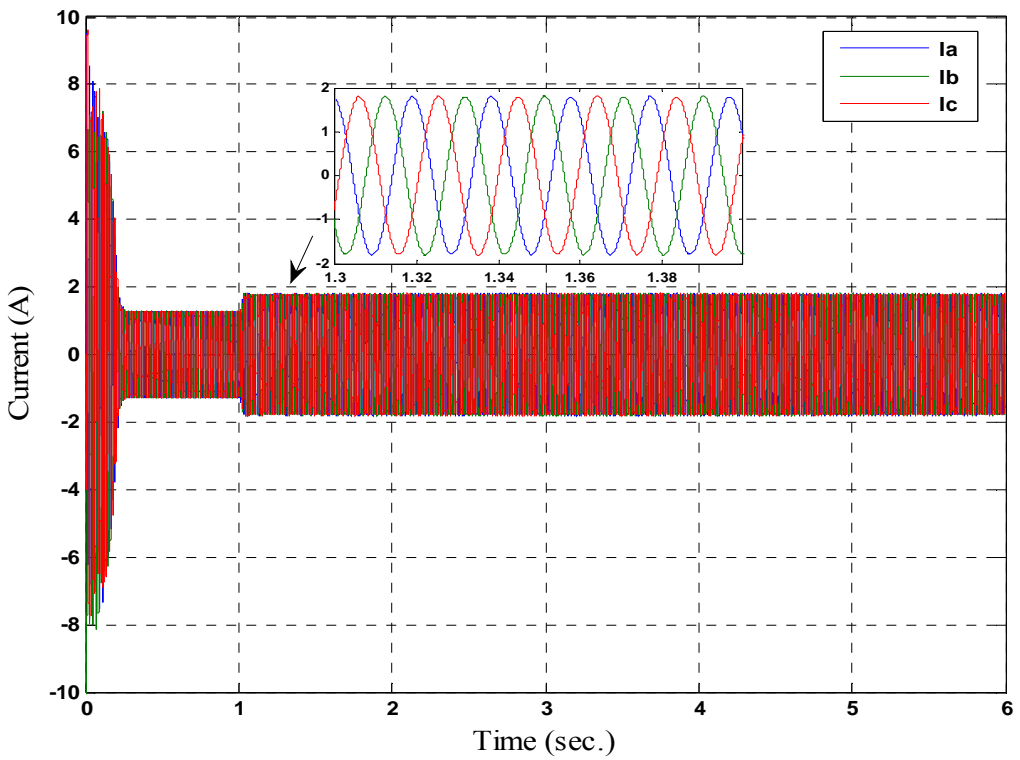

FIG. 9. CURRENT RESPONSE OF FUZZY LIKE PI CONTROLLER 


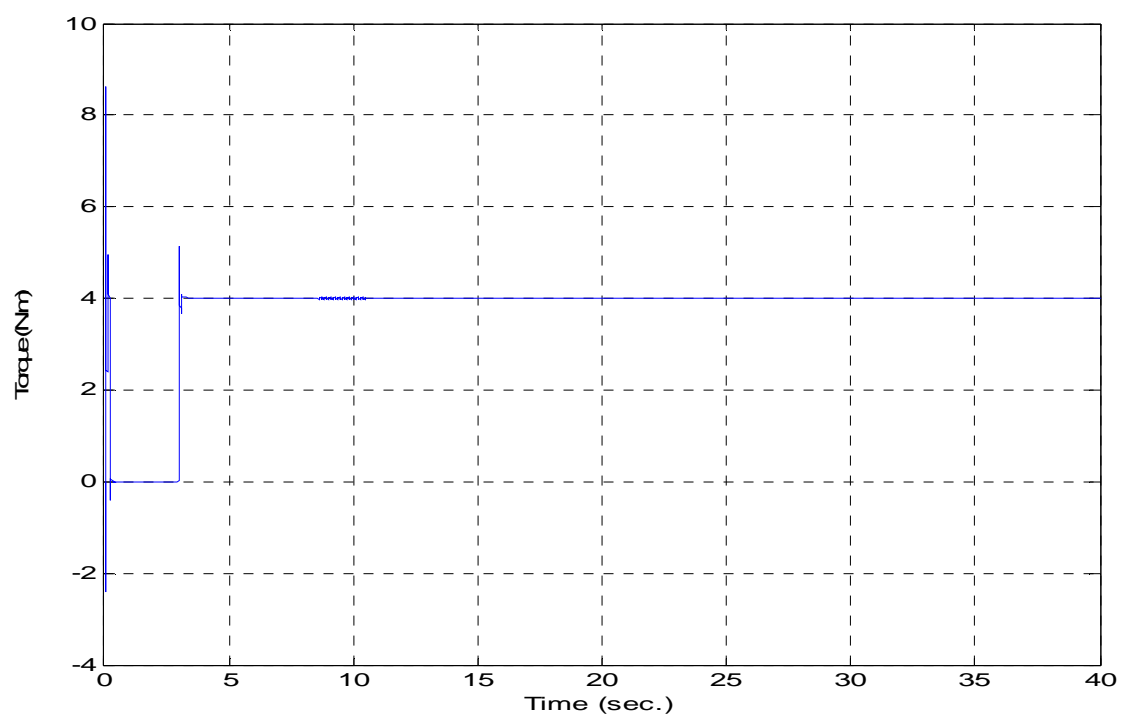

FIG. 10. TORQUE RESPONSE OF FUZZY LIKE PI CONTROLLER

Fig.11 shows the frequency response from the controller, it can be recognized that the frequency increases after applying the load; the Fuzzy like PI controller raised the frequency more quickly than the PI controller. Fig.12 shows the speed response of both PI and Fuzzy like PI controllers where the motor runs with a speed equals to $1500 \mathrm{rpm}$. Then, after applying a load torque which equals 4 N.m, the speed decreases to 1378 , where the PI controller speed response takes more time to reach the refrence speed, the Fuzzy like PI controller produces better performance, where the overshoot is nearly removed and the settling time is faster compared to the PI speed controller. The results confirm that the Fuzzy like PI controller can provide more effective and robust speed tracking performance as compared with the PI controller.

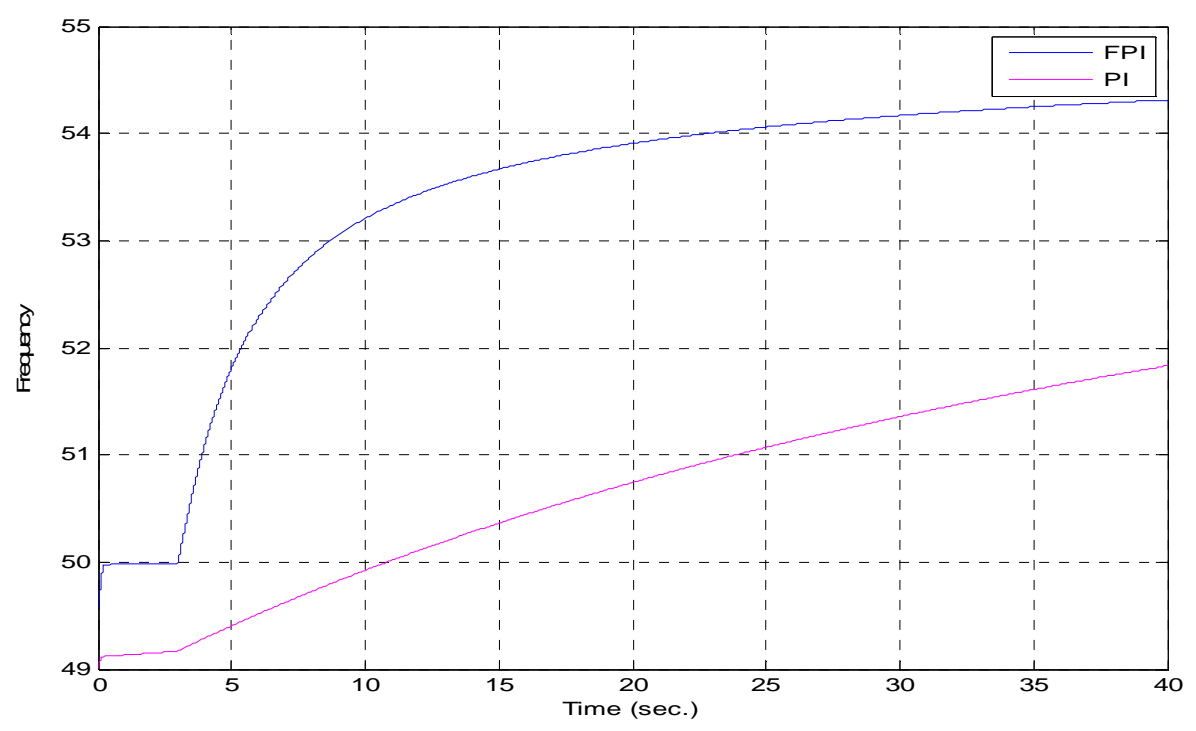

FIG. 11: FREQUENCY FROM THE CONTROLLER 


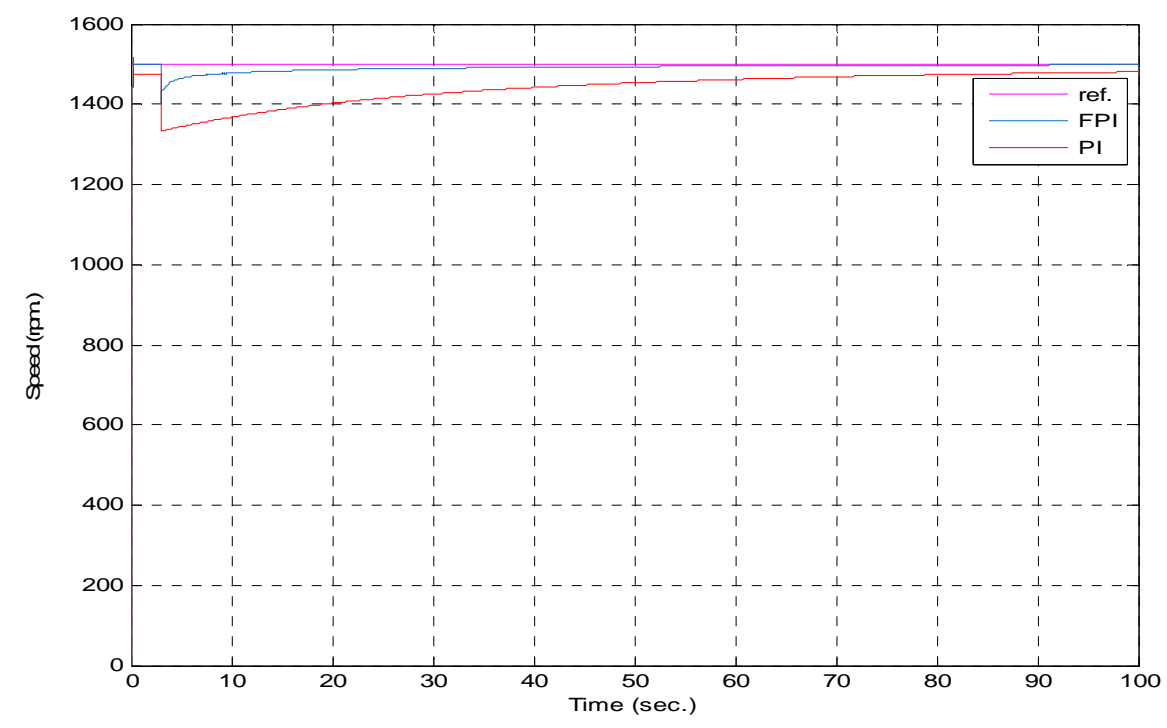

FIG. 12: SPEED RESPONSE OF FUZZY LIKE PI AND PI CONTROLLER

Fig.13a, Fig.13 b, Fig.13 $c$ and Fig.13d show the response from the SVPWM invertor.

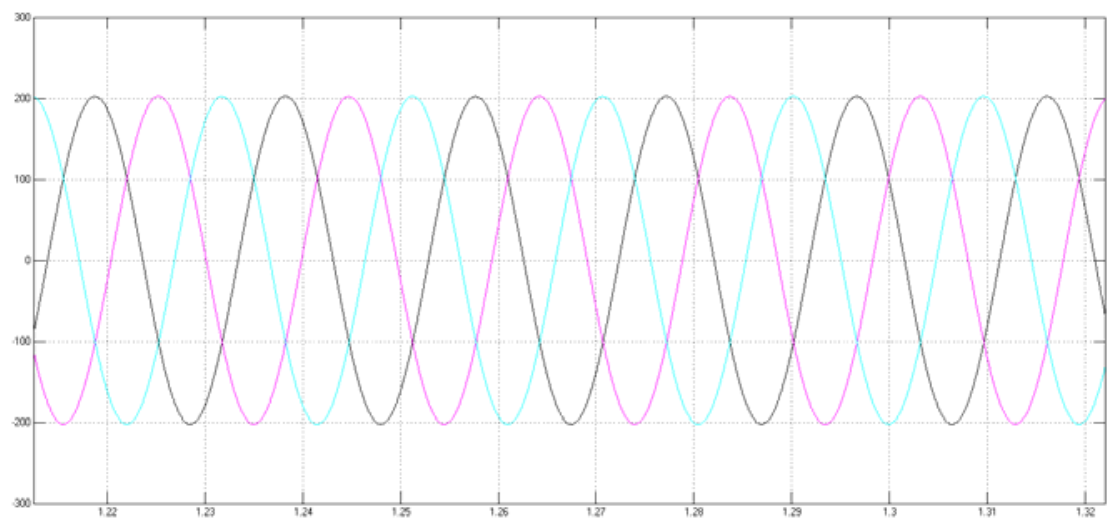

Fig. 13 A: The three Phase voltage (VA, VB, VC)

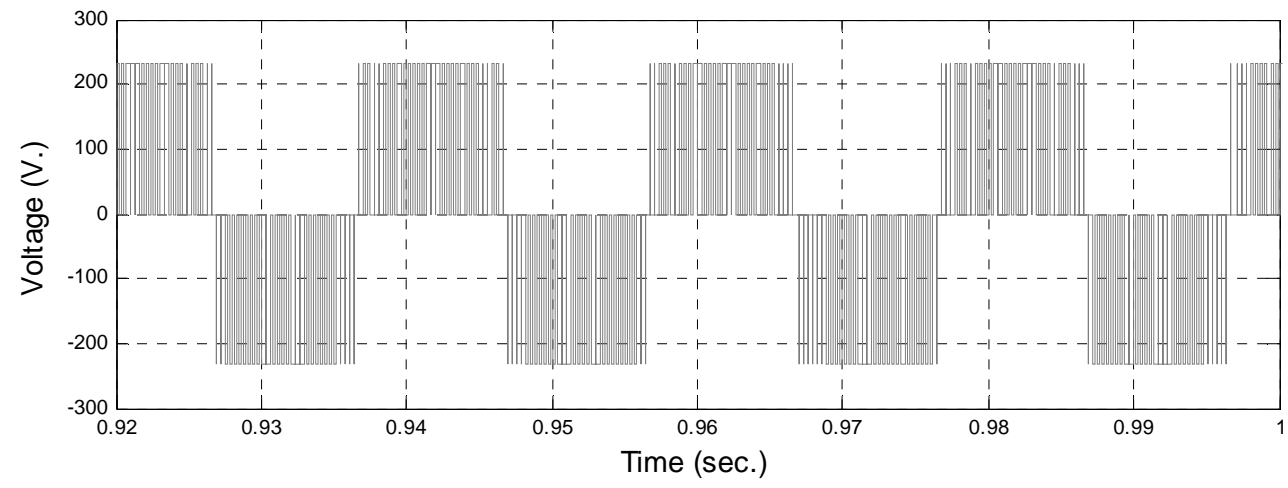

Fig 13. B : Svpwm $\mathbf{V}_{\text {iAB }}$ VOltage before filtering. 


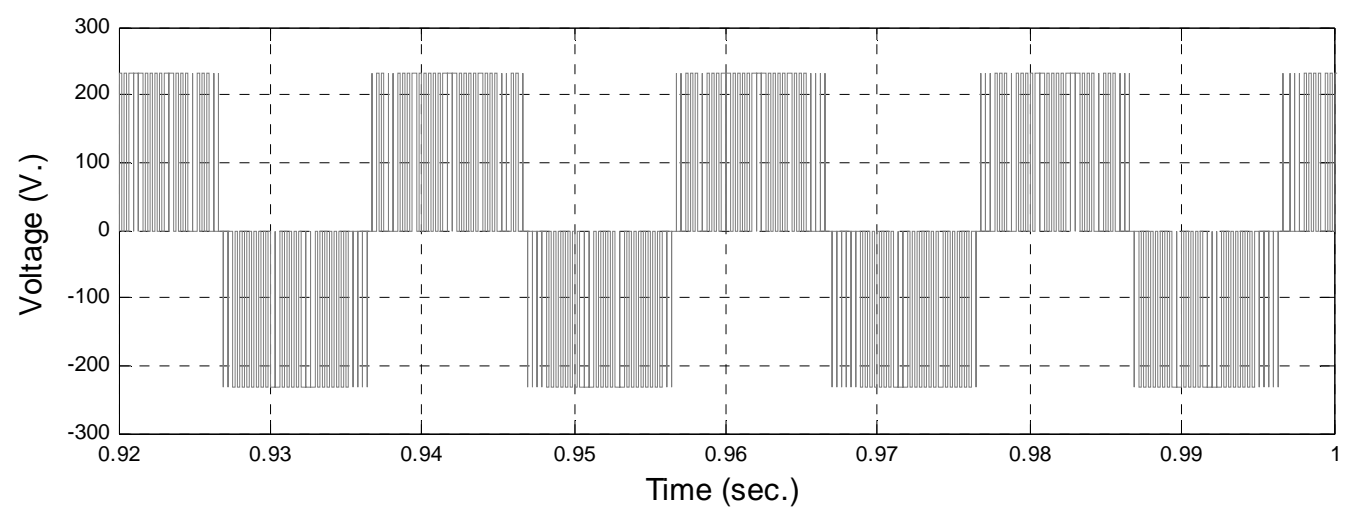

FIG 13. C : Svpwm V V ibc Voltage Before Filtering.

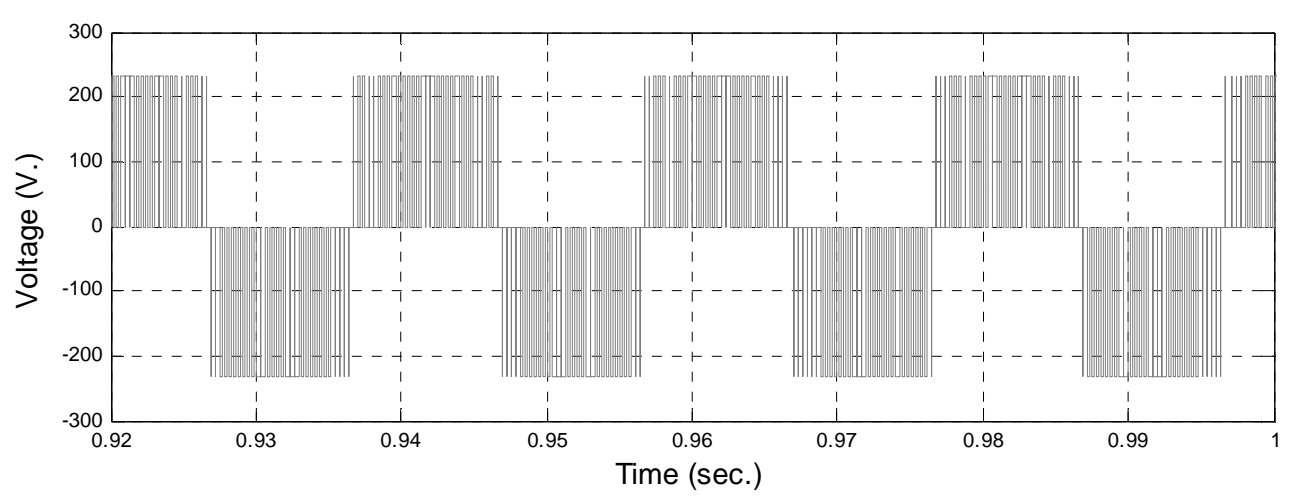

FIG 13. D : SVPWM V ica VOLTage BEFore FiLtering.

\section{CONCLUSION}

In this paper, an intelligent controller, which is the Fuzzy like PI controller, is presented and the FOC strategy is used. The performance of the Fuzzy like PI speed controller has been established and compared with that of the conventional PI controller. The simulation results proved that the Fuzzy like PI controller can provide better and more robust performance under load variation. When the motor was running with a speed equals to $1500 \mathrm{rpm}$, an external load was applied at time $=3$ sec., the frequency result from the controller increased when the load was applied, while the speed decreased and the used controller attempted to raise it to the reference speed. The simulation result showed that the Fuzzy like PI controller raised the frequency more quickly than the PI controller. It can be concluded that the proposed intelligent speed controller has presented a superior performance over that of the classical PI controller.

\section{NOMENCLATURE}

$\begin{array}{clc}\text { B } & \text { coefficient of viscous friction } & \mathrm{Nm} /(\mathrm{rad} / \mathrm{s}) \\ i_{d s}, i_{q s} & \text { d and q axis components of the stator currents } & \mathrm{Amp} . \\ \mathrm{J} & \text { moment of Inertia } & \mathrm{Kg} \cdot \mathrm{m}^{2} \\ L_{s}, L_{r} \& L_{m} & \text { stator, rotor and mutual inductances } & \mathrm{H} \\ \mathrm{P} & \text { number of poles. } & \text { none } \\ R_{S} & \text { stator resistance of IM } & \Omega \\ R_{r} & \text { rotor resistance of IM } & \Omega\end{array}$




$\begin{array}{clr}T_{e} & \text { torque developed in the IM } & \text { N.m } \\ T_{L} & \text { external load torque } & \text { N.m } \\ v_{d s}, v_{q s} & \text { stationary direct and quadrature stator voltage } & \text { Volt. } \\ \Omega r & \text { rotor speed } & \mathrm{rad} / \mathrm{sec} .\end{array}$

$\lambda d_{r}$ and $\lambda q_{r} \quad$ the $\mathrm{d}$ and $\mathrm{q}$ axis components of the rotor fluxes $\mathrm{Wb}$

\section{Acronyms}

Acronyms
FLC
FOC
IM
PWM
SVPWM

\author{
Definition \\ Fuzzy Logic Control \\ Field Oriented Control \\ Induction Motor \\ Pulse Width Modulation \\ Space-Vector Pulse Width Modulation
}

\section{REFERENCES}

[1] Habbi, H. M. D., Ajeel, H. J., \& Ali, I. I. (2016). Speed Control of Induction Motor using PI and V/F Scalar Vector Controllers. International Journal of Computer Applications, 151(7).

[2] Mishra, A. (2012). dDesign of Speed Controller for Squirrel-cage Induction Motor using Fuzzy Logic based Techniques. International Journal of Computer Applications, 58(22).

[3] Tripura, P., \& Babu, Y. S. K. (2011). Fuzzy logic speed control of three phase induction motor drive. World Academy of Science, Engineering and Technology, 60(3), 1371-1375.

[4] Mannan, M. A., Murata, T., Tamura, J., \& Tsuchiya, T. (2005). Fuzzy-logic-based self-tuning PI controller for speed control of indirect field-oriented induction motor drive. Transactions of the Society of Instrument and Control Engineers, 41(8), 637-644.

[5] Tunyasrirut, S., Suksri, T., \& Srilad, S. (2007). fFuzzy logic control for a speed control of induction motor using space vector pulse width modulation. a a, $5(2 \mathrm{~V}), 2$.

[6] Salima, M., Riad, T., \& Hocine, B. (2008). APPLIED INPUT-OUTPUT LINEARIZING CONTROL FOR HIGHPERFORMANCE INDUCTION MOTOR. Journal of Theoretical \& Applied Information Technology, 4(1).

[7] Nageswara Rao .M. and Rajani. A. 'Speed Control of Induction Motor Using Fuzzy Logic Approach” August - 2013, International Journal of Engineering Research \& Technology (IJERT) Vol. 2 Issue 8.

[8] Menghal, P. M., Laxmi, A. J., \& Anusha, D. (2014). SPEED CONTROL OF INDUCTION MOTOR USING FUZZY LOGIC CONTROLLER. i-Manager's Journal on Electrical Engineering, 8(2), 21.

[9] Devi, K., Singh, R., Gautam, S., \& Nagaria, D. (2015). Speed control of induction motor using fuzzy logic approach. International Journal, 3(4), 694-697.

[10] TEENA P. and MAHAJAN. P. 2016 'Control of induction motor using fuzzy logic, pi controller and pid controller" International Conference, 3rd July, 2016, Pune, India, ISBN: 978-93-86083-51-7.

[11] Fattah, A. (2015). "Design and Analysis of Speed Control Using Hybrid PID-Fuzzy Controller for Induction Motors". Master's Theses. 595.

[12] Vengatesan V. and Chindermani .M , (Speed Control of Three Phase Induction Motor Using Fuzzy Logic Controller by Space Vector Modulation Technique', 2014, International Journal of Advanced Research in Electrical, Electronics and Instrumentation Engineering (An ISO 3297: 2007 Certified Organization) Vol. 3, Issue 12.

[13] Jung, J. W., \& DStudent, P. H. (2005). PROJECT \#2 Space vector PWM inverter. Mechatronic Systems Laboratory, Dept. of Electrical and Computer Eng. The Ohio State University.

[14] Ms.P. S. Raichurkar, Mr. A.L.Jamadar , "V/F Speed Control of 3 phase Induction Motor using Space Vector Modulation", May-2015, International Journal of Engineering Research \& Technology (IJERT), ISSN: 2278-0181, Vol. 4 Issue 05 .

[15] Wiam I. Jabbar," dDirect Torque Control of Induction Motor Based on Intelligent Techniques" University of Technology, 2013, Iraq, MSc. thesis.

[16] Kalhoodashti, Hossein Ebadi, and Mehdi Shahbazian. "Hybrid speed control of induction motor using PI and fuzzy controller." International Journal of Computer Applications 30.11 (2011): 44-50.

[17] Kumar, R. A. and Daya, J. L. F., a nNovel self- tuning fuzzy based PID controller for speed control of induction motor drive', 2013, International conference on control communication and computing (ICCC),62-67. 